\title{
Thermal diagnostics of oil-filled equipment under operating voltage
}

\author{
B.R. Kangozhin*, S.S. Dautov, M.S. Zharmagambetova and M.A. Kosilov \\ Kazakh Academy of Transport and Communications named after M.Tynyshpaev, \\ 97, Shevchenko Str.,050012, Almaty, Kazakhstan \\ *e-mail: almaty_bek@inbox.ru
}

\begin{abstract}
The article justifies the need for technical diagnostics of high-voltage insulation of electrical equipment under operating voltage. The thermal imaging monitoring method of equipment condition is considered in the document. It is shown that by means of rejection criterion $\left(\operatorname{tg} \delta_{\text {MEAS }}-\operatorname{tg} \delta_{\text {PLANT }}\right)$ defects in an initial stage of development come to light. The efficiency of control of high-voltage paper-oil insulation under operating voltage has been experimentally proved. The analysis of the causes of damage to high-voltage bushings and current transformers of $500 \mathrm{kV}$, based on which it was revealed that local defects are characteristic, the development of which leads to either thermal breakdown or the appearance of partial discharges and electrical breakdown of the main insulation. Thermal imaging diagnostics of such equipment as, for example, high-voltage bushings, coupling capacitors and current transformers makes it possible to detect almost all possible defects in insulation and measure their insulation characteristics. The efficiency of thermal imaging monitoring of the state of electrical equipment under operating voltage is shown. The calculated $\operatorname{tg} \delta$ values from thermal imaging measurements are more accurate, since the results of measurements with a thermal imager are not affected by electromagnetic interference.It has been concluded that it is possible to abandon several traditional methods of testing with shutdown and without electrical equipment.
\end{abstract}

Key words: thermal imaging control, paper-oil insulation, dielectric loss tangent, energized equipment, insulation damage, rejection criterion.

PACS numbers:

\section{Introduction}

The development time of most locally concentrated defects from appearance to damage of electrical insulation has not been studied and can only be estimated tentatively. But such defects are the main cause of damage to the equipment [1]. Defects cannot be ruled out. It is possible to eliminate damage of equipment by detecting and eliminating dangerous defects at an early stage of development, organizing continuous monitoring of occurrence and development of dangerous defects [2,3]. Methods of diagnostics of electrical equipment under operating voltage are required for this purpose [4].

\section{Methods}

By researches of paper-oil isolation with local defect, inputs and a TT, it is established if there is local defect the size $\operatorname{tg} \delta$ depends on tension, as it must be used for timely identification of defect (Figure 1). If there is a local defect even with a strong degree of its development, when the insulation paper is charred from the heat generated in the place of the defect, the total value of the dielectric loss tangent changes slightly at measurements at UExec $=10 \mathrm{kV}$ [5].

The results of insulation measurements with local defect (Figure 1.) can be calculated using the Formula [6]:

$$
\operatorname{tg} \delta=\frac{\operatorname{tg} \delta_{N} \times C_{N}+\operatorname{tg} \delta_{\text {Д }} \times C_{\text {Д }}}{C_{N}+C_{\text {Д }}},
$$

If the following parameters for insulation parcels are specified:

$$
\begin{gathered}
\operatorname{tg} \delta_{N}=0,1 \%, \operatorname{tg} \delta_{\text {म }}=100 \% \\
C_{N}=0,999, C_{\text {д }}=0,001
\end{gathered}
$$

$\mathrm{N}$ - insulation volume without defect;

D - volume of insulation with defect, 
then calculations by Formula (1) will give the following result:

$$
\operatorname{tg} \delta=\frac{\operatorname{tg} \delta_{N} \times C_{N}+\operatorname{tg} \delta_{\text {Д }} \times C_{\text {Д }}}{C_{N}+C_{\text {Д }}}=0,2 \%
$$

Other words, prior to the occurrence of the local insulation defect tg $\delta$ at $10 \mathrm{kV}$ was $0.1 \%$, and the occurrence of the highly developed defect $\left(\operatorname{tg} \delta_{\text {д }}=\right.$ $100 \%$ ) changed the total or measured tg $\delta$ to only $0.2 \%$, which is within the inaccuracy and will not cause doubt in the normal insulation state [7]. However, the occurrence of a local defect with $\operatorname{tg} \delta=$ $100 \%$ or more will lead to local intense heat generation, paper charring and the creation of a conductive channel in this zone. That means it can also lead to the classic heat breakdown. The difference between $\operatorname{tg} \delta$ insulation with and without defect was $0.1 \%$. Therefore, it is possible to accept the size of rejection criterion $\left(\operatorname{tg} \delta_{\text {MEAS }}-\operatorname{tg} \delta_{\text {PLANT }}\right)$ considering an error of measurements more or equal to $\geq 0,3 \%$.

$$
\Delta \operatorname{tg} \delta=\operatorname{tg} \delta_{\text {РАБ. }}-\operatorname{tg} \delta_{10 \mathrm{kB}} \geq 0,3 \%
$$

The difference in $\operatorname{tg} \delta$ values at two voltage levels of $0.3 \%$ or more indicates the development of a local defect, and the apparatus with such insulation should be rejected [8]. It is the difference in $\operatorname{tg} \delta$ values at two voltage levels of $0.3 \%$ and more that should be a rejection criterion when diagnosing machines with paper-oil insulation.

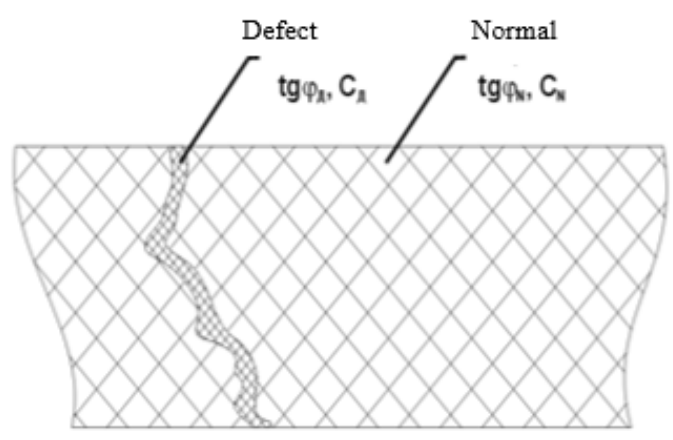

Figure 1 - Insulation area with local defect

The essence of the method is obvious from Figure 2. Measurements of $\operatorname{tg} \delta$ value of each product concerning the object chosen for a standard are performed. The received $\operatorname{tg} \delta$ values are the difference of $\Delta \operatorname{tg} \delta_{\text {MEAS }}=\operatorname{tg} \delta_{\text {Ио }}-\operatorname{tg} \delta_{\text {эт }}(\mathrm{MO}-$ measured object,
$\mathrm{RO}$ - reference object) which can have both positive, and negative values depending on absolute $\operatorname{tg} \delta$ values of the compared objects. True values of $\operatorname{tg} \delta_{\text {Ист }}$ of the measured object are determined by adding the following sign $\Delta \operatorname{tg} \delta=\Delta \operatorname{tg} \delta_{\text {MEAS }}$ with $\operatorname{tg} \delta$ (Figure 2) obtained during measurements:

$$
\operatorname{tg} \delta_{\text {ИСТ }}=\left( \pm \Delta \operatorname{tg} \delta_{\text {MEAS }}\right)+\operatorname{tg} \delta_{\ni T}
$$

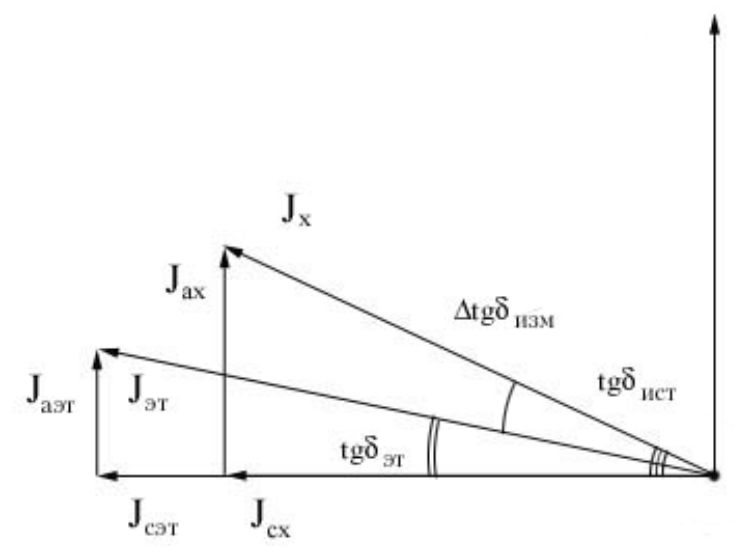

Figure 2 - The vector chart of measurements by the bridge with use of a standard with $\operatorname{tg} \delta_{\ni \mp} \neq 0 \%$.

The insulation condition is evaluated by comparing the results of the first measurements with the plant measurements and the subsequent measurements with the first measurements [10]. Rejection indicator is the difference at the first measurement on $\Delta \operatorname{tg} \delta=\operatorname{tg} \delta_{\text {MEAS }}$ - $\operatorname{tg} \delta_{\text {PLANT }} \geq 0,3 \%$, and at the subsequent: $\Delta \operatorname{tg} \delta=\operatorname{tg} \delta_{\text {MEAS }}-\operatorname{tg} \delta_{1 \text { MEAS }} \geq 0,3 \%$.

Transformer groups input and 220-500 kV current transformers on Ekibastuz GRES-2 have paper-oil insulation (POI). Based on the analysis of the causes of damage to the inlets and TT, it was revealed that local defects are characteristic, the development of which leads to either thermal breakdown or partial discharge and electrical breakdown of the main insulation. As an axiom, it is assumed that aging of insulation leads to deterioration of its insulation characteristics. However, the operating experience shows that isolation in which there was no local defect, for example, of the moistening causing change of $\operatorname{tg} \delta$, the value $\operatorname{tg} \delta$, remains stable during all service life of the device [11].

At thermal imaging inspection of current transformer, condensers of communication, capacitive transformers of tension under the operating voltage the defects leading to increase in 
the dielectric losses in isolation determined by a tangent of angle of dielectric losses ( $\operatorname{tg} \delta$ ) and causing temperature increase of isolation $[12,13]$ come to light. The temperature of the external surface of such devices should be higher than that of serviceable ones. Measurements under the operating voltage can be carried out at any ambient temperature as the difference is measured in the size $\operatorname{tg} \delta$ of the inputs having identical dependence of $\operatorname{tg} \delta=\mathrm{f}(\mathrm{T})$. With such measurements and the use of factory measurement data as reference characteristics having the same temperature, it is not necessary to perform a temperature recalculation to the temperature of measurements at the plant to calculate the data of the measured object. This recalculation is carried out automatically as the temperature dependence of $\operatorname{tg} \delta$ of a standard and the measured object is identical [14].

The estimation of oil-filled devices with condenser insulation is estimated by the value of the device temperature exceeding the average ambient temperature $[15,16]$ :

$$
\Delta \mathrm{T}_{\mathrm{i}}=\mathrm{T}_{\mathrm{i}}-\mathrm{T}_{0},
$$

Where $T_{i}-$ the temperature of the apparatus determined by the area of the external surface characteristic of each type of equipment; $T_{0}$ is the average ambient temperature determined for each equipment type.

Thermal imaging diagnostics of such devices as condensers of communication and transformers of current, allows not only to reveal, practically, all possible defects, but also to measure their insulating characteristics $(\operatorname{tg} \delta)$. Recalculation of the excess of temperature of a surface of the device over ambient temperature measured by the thermal imager in value of insulating characteristic $(\operatorname{tg} \delta)$ is made on a formula [15]:

$$
\operatorname{tg} \delta_{x}=\frac{\operatorname{tg} \delta_{\ni} \times\left(T_{x}-T_{0}\right)}{\left(T_{\ni x}-T_{0}\right)},
$$

For recalculation the data of measurements under the operating voltage of $\operatorname{tg} \delta$ by a bridge method of measurement (direct measurements) are used $[17,18]$. At measurements on temperature (indirect measurements) the device connected to any phase unlike the bridge scheme of direct measurement $\operatorname{tg} \delta$ when the standard must be connected only to the same phase of electro installation can be taken for a standard [19]. At JSC "EGRES-2 Station" thermal imaging diagnostics of high-voltage devices 220$500 \mathrm{kV}$ with POI of capacitor type: current transformers, communication capacitors, highvoltage inputs were performed. By results of thermal imaging diagnostics $\operatorname{tg} \delta$ values of all listed devices are calculated [20]. At the same time, the calculated values for thermal imaging measurements are more accurate, as the results of measurement by the thermal imager are not affected by electromagnetic interference.

\section{Experiment results}

Here are two examples of the thermal imaging survey results which were performed by an infrared camera ThermoPro ${ }^{\mathrm{TM}}$ by Wuhan Guide Infrared Technology Co., Ltd [19]. They show the efficiency of thermal imaging monitoring of electrical equipment under operating voltage.

Example 1. By results of measurement of temperature of a surface of TT-2 (Figure 3) calculation of $\operatorname{tg} \delta$ of the main isolation of a TT is executed (Table1).

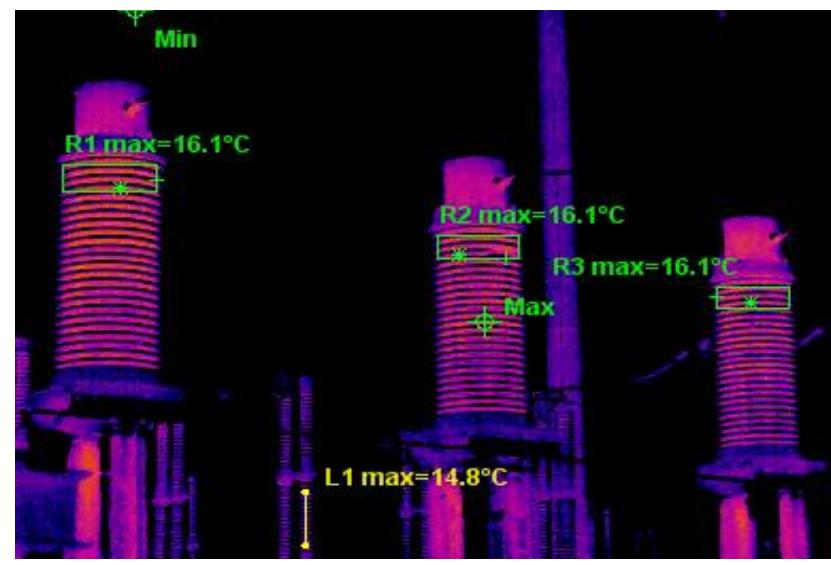

Figure 3 - Results

Thermal imaging transformers

$220 \mathrm{kV}$ current TT-2

Phase TT-2 thermogram C, B, A.

$$
\begin{aligned}
& \mathrm{T}_{\mathrm{C}}=16,1^{\circ} \mathrm{C} ; \\
& \mathrm{T}_{\mathrm{B}}=16,1^{\circ} \mathrm{C} ; \\
& \mathrm{T}_{\mathrm{A}}=16,1^{0} \mathrm{C}
\end{aligned}
$$


Table 1 - Temperature measurements of $220 \mathrm{kV}$ current transformers TT-2 by thermograms:

\begin{tabular}{|c|c|c|c|c|}
\hline $\begin{array}{c}\text { Transformer } \\
\text { Phase }\end{array}$ & Тмах, ${ }^{0} \mathrm{C}$ & $\Delta \mathrm{T},{ }^{0} \mathrm{C}$ & $\begin{array}{c}\operatorname{tg} \delta, \% \\
\text { (расч.) }\end{array}$ & $\begin{array}{c}\operatorname{tg} \delta, \% \\
\text { (изм.) }\end{array}$ \\
\hline $\mathrm{A}$ & $16,1^{0} \mathrm{C}$ & 0,00 & 0,32 & 0,35 \\
\hline $\mathrm{B}$ & $16,1^{0} \mathrm{C}$ & 0,00 & 0,32 & 0,34 \\
\hline $\mathrm{C}$ & $16,1^{0} \mathrm{C}$ & 0,00 & 0,32 & 0,32 \\
\hline
\end{tabular}

Calculated values of $\operatorname{tg} \delta$ TT- 2 meet Standards and requirements of manufacturer. There are no defects that cause temperature change of $220 \mathrm{kV}$ TT2 current transformers in $220 \mathrm{kV}$ current transformers TT-2 phases A, B and C. Similar results have been obtained in the diagnosis of other devices with POI.

Example 2. By results of temperature of condenser surface CC-220 PTL 2377 ODD-220 measurement (Figure 4) calculation of $\operatorname{tg} \delta$ for elements of condensers of communication CC-220 PTL 2377 ODD-220 is executed (see Table 2).

Design values of voltage distribution and nonuniformity coefficient of communication capacitor CC-220 PTL 2377 ODD-220 do not comply with the Standards and requirements of the manufacturer. The lower element CC-220 PTL 2377 ODD-220 has a defect in the initial stage of development, the upper element has no defects which cause a change in its temperature

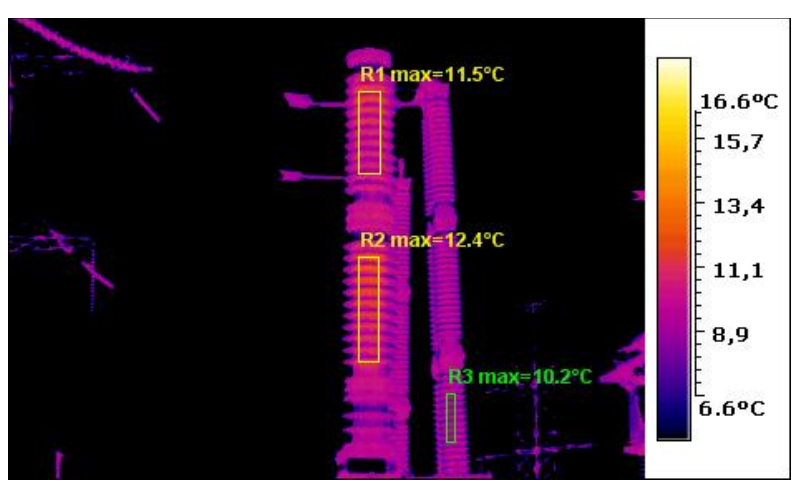

Figure 4 - The results of thermal imaging survey of CC-220 PTL 2377 ODD-220. Thermograph CC-220 PT: 2377 ODD-220, C Phase. $\mathrm{T}_{\mathrm{UP}}=11,5^{\circ} \mathrm{C}$; $\mathrm{T}_{\text {DOWN }}=12,4^{\circ} \mathrm{C}$.

Table 2 - Results of temperature measurements and voltage distribution by elements of communication capacitor CC220 PTL 2377 ODD-220 by thermograms

\begin{tabular}{|c|c|c|c|c|c|}
\hline $\begin{array}{c}\text { Transformer } \\
\text { Phase }\end{array}$ & ${ }^{\mathrm{T} M a x},{ }^{0} \mathrm{C}$ & $\Delta \mathrm{T},{ }^{0} \mathrm{C}$ & $\begin{array}{c}\mathrm{U} \text { el, } \mathrm{kV} \\
\text { (calc.) }\end{array}$ & $\mathrm{K}_{\mathrm{H}}$ & $\begin{array}{c}\text { tg } \delta, \% \\
\text { (calc.) }\end{array}$ \\
\hline $\mathrm{Up}$ & $11,5^{0} \mathrm{C}$ & 1,3 & 47,2 & \multirow{2}{*}{1,7} & 0,3 \\
\hline Down & $12,4^{0} \mathrm{C}$ & 2,2 & 79,8 & - & 1,4 \\
\hline $\mathrm{T}_{\text {ОКР }}{ }^{0} \mathrm{C}$ & $10,2^{0} \mathrm{C}$ & - & - & - & - \\
\hline
\end{tabular}

For a thermal imaging way of electric devices condition control dependences of tg $\delta$ on temperature by any of the known ways decide on POI. For real measurements of TT-500 kV:

- $\operatorname{tg} \delta_{\text {Plant }}$ values are selected according to $\Delta \mathrm{T}=0^{\circ} \mathrm{C}: 0,21,0,19,017,019,0,21,0,21,0,21$.

- $\operatorname{tg} \delta_{\text {PLANT }}$ values are selected according to $\Delta \mathrm{T}=0.1^{\circ} \mathrm{C}: 0,27,0,27,0,27,0,27,0,27$.

- Max $\operatorname{tg} \delta_{\text {PLANT }}$ values are selected according to $\Delta \mathrm{T}=0^{\circ} \mathrm{C}: 0,21$ and $\operatorname{tg} \delta_{\text {PLANT }}$ values are selected according to $\Delta \mathrm{T}=0,1^{\circ} \mathrm{C}: 0,27$, as $\operatorname{tg} \delta_{\text {MEAS }}$ cannot be less than tgס $\delta_{\text {PLANT. }}$
The ratio is defined $\Delta \mathrm{T}=0,1^{\circ} \mathrm{C}$ and value of $\operatorname{tg}$ according to:

$\operatorname{tg} \delta_{\text {PLANT }} 0,1^{\circ} \mathrm{C}-\operatorname{tg} \delta_{\text {PLANT }} 0^{\circ} \mathrm{C}=0,27-0,21=0,06$, that is $\Delta \mathrm{T}=0,1^{\circ} \mathrm{C}$ refers to $\operatorname{tg} \delta=0,06 \%$;

Then the empirical formula has the form is:

$$
\begin{gathered}
\left(\operatorname{tg} \delta_{\text {PLANT }} \text { for } \Delta \mathrm{T}=0^{\circ} \mathrm{C}\right)+ \\
\left(\operatorname{tg} \delta_{\text {PLANT } 0,1^{\circ} \mathrm{C}-\operatorname{tg} \delta_{\text {PLANT }} 0^{\circ} \mathrm{C}}\right)
\end{gathered}
$$

or:

$$
\operatorname{tg} \delta_{\mathrm{PACY}}=\operatorname{tg} \delta_{\mathrm{PLANT}} 0^{\circ} \mathrm{C}+0,06 \cdot \Delta \mathrm{T}(\%) .
$$

As a sample:

$$
\operatorname{tg} \delta_{\mathrm{PACY}}=0,21+0,06 \cdot \Delta \mathrm{T}(\%)
$$




\section{Discussions}

The main thing when selecting the value of $\operatorname{tg} \delta_{\text {PLANT }}$ refers to a certain $\Delta \mathrm{T}$ is that the $\operatorname{tg} \delta_{\text {MEAS }}$ cannot have a value less than $\operatorname{tg} \delta_{\text {PLANT. }}$. The fact that some values of tg $\delta_{\text {PLANT }}$ for $\Delta \mathrm{T}=0^{\circ} \mathrm{C}$ are slightly less (in this sample 0.17 and 0.19 ) than the maximum value of 0.21 can be related to two circumstances:

1. The temperature measurement accuracy of the thermal gauge is $\Delta \mathrm{T}=0.1^{\circ} \mathrm{C}$, which in the example is $\Delta \operatorname{tg} \delta=0.06 \% \operatorname{tg} \delta$ can be measured with an accuracy $0.06 \%$ and it is not possible to distinguish smaller values of $\operatorname{tg} \delta$ (in a given sample $0.02 \%$ and $0.04 \%)$.

2. During operation there were minor changes in $\operatorname{tg} \delta$ measured TT $(0.02 \%$ and $0.04 \%$ in this sample).

\section{Conclusions}

1. Change of $\operatorname{tg} \delta_{\text {MEAS }}$ concerning $\operatorname{tg} \delta_{\text {PLANT }}$ is rejection criterion and allows to reveal existence of defect in initial extent of development. The use of the high-voltage paper-oil insulation control technique allows to eliminate all other types of tests, at least until the controlled parameters reach the limit values.

2. The thermal imaging method allows by converting the measured temperature differences into insulation characteristics (tgd), measured by direct measurement under operating voltage, to assess the condition of the object under examination, to detect defects in it and to determine the degree of their development.

3. The thermal imaging examination method allows to detect defects at an early stage of their development, as well as provides additional diagnostic criteria. In addition, this method allows the detection of defects that cannot be detected by any other test methods. Based on an analysis of the causes of damage to high-voltage bushings of transformers and current transformers, it is revealed that local defects are characteristic, the development of which leads either to thermal breakdown or to the appearance of partial discharges and electric breakdown of the main insulation.

4. Measurements under operating voltage can be performed at any ambient temperature, since the difference in the value of $\operatorname{tg} \delta$ of inputs having the same dependence $\operatorname{tg} \delta=\mathrm{f}(\mathrm{T})$ is measured. With such measurements and using factory measurements as characteristics of a standard having the same temperature, it is not necessary to perform temperature conversion to the measurement temperature at the factory to calculate the data of the measured object. This recalculation is performed automatically, since the temperature dependence $\operatorname{tg} \delta$ of the standard and the measured object is the same.

\section{References}

1. Statistical data on defects in high-voltage equipment at substations of JSC "FGC UES" and IDGC Holding. (2016).

2. RD 34.45-51.300-97 (1998). Electrical Equipment Test Scope and Standards. (6 ${ }^{\text {th }}$ ed.). Moscow: ENAS.

3. On measures to improve the reliability of hermetic bushings 110-750 kV (1988). Emergency Circular N C -0688E. -Moscow: GN-TU USSR Ministry of Energy.

4. Polyakov V.S. (June 21-26, 2004). Principles of building an effective diagnostic system. (27 th ed.). Materials of the seminar "Modern problems of production, operation and repair of transformer equipment". St. Petersburg: PEIPK, 196.

5. Polyakov V.S. (June 5-9, 2000). Analysis of the requirements of the Test Norms for the diagnosis of oil-filled equipment. $\left(11^{\text {th }}\right.$ ed.). Materials of the seminar "Current state and problems of diagnostics of powerful power transformers and shunt reactors”. St. Petersburg: PEIPK, 387.

6. Tsirel Ya.A., Polyakov V.S., Smerling L.A.. Measurement of dielectric losses of high voltage inputs under operating voltage. (1975). Journal of Power Stations, 2.

7. Polyakov V.S. (June 25-29, 2004). Analysis of measurement schemes of insulation characteristics of high-voltage bushings and current transformers under operating voltage. $\left(16^{\text {th }}\right.$ ed.). Materials of the seminar "Modern problems of operation of high-voltage oil-filled equipment". St. Petersburg: PEIPK, 194.

8. Polyakov V.S., Utegulov N.I. System for continuous monitoring of the isolation of high-voltage electrical equipment. (2009). Bulletin of the Almaty Institute of Energy and Communications (AIEIS), 3, 4-10.

9. RD 34.20.501-95. (2000). Rules for the technical operation of power plants and networks.(15 ${ }^{\text {th }}$ ed.). St. Petersburg: Dean, 352.

10. Monastyrskyi A.E. Insulation monitoring system for SKIT transformers. (2001). Journal of Technical description and operating manual. St. Petersburg: LLC Dizkon. 
11. Ya.A. Tsirel, V.S. Polyakov, L.A. Smerling. Measurement of dielectric losses of high-voltage bushings under operating voltage. (1975). Journal of Electric Stations, 2.

12. Polyakov V.S. The use of infrared technology to detect defects in high-voltage equipment. (1985). Journal of Energy and Electrification. Series: Operation and repair of electrical networks. Express information. Moscow: SPO Soyuztekhenergo, 7.

13. Polyakov V.S. The use of thermal imaging detectors for detecting defects in high-voltage equipment. (1990). Methodological instructions for monitoring equipment with thermal imaging devices. Leningrad: LIPKEN, 57.

14. Afonin A.V., Polyakov V.S., et al. Infrared thermography in power engineering. (2000) Fundamentals of infrared thermography. Vol. 1. St. Petersburg: PEIPK.

15. RD 153-34.0-20.363-99. Basic provisions of infrared diagnostics of electrical equipment и AL (ORGRES).

16. RD EO-0188-00. Guidelines for the diagnosis of electrical apparatus of switchgear of power plants and substations. (1999). Section 2: "Thermal imaging control of switchgear devices". Rosenergoatom Concern. Ministry of the Russian Federation for Atomic Energy. Moscow.

17. Vorobyov S.A. Electrical measurements of non-electrical quantities. (1975). Vol. 2. The fundamentals of the theory and calculation of unbalanced bridge circuits of the resistance-sensor. Sverdlovsk: UPI after named C.M. Kirova, 232.

18. Swee P.M. Methods and diagnostic tools for high voltage equipment. (2012). Moscow: Energoatomizdat, 240.

19. Vavilov V.P. Infrared thermographic diagnostics in construction and power engineering. (2014). Moscow: Energoprogress, 186.

20. Ekibastuz Report № 01-05-1067-0015 «System of diagnostics of electrical equipment of JSC "Ekibastuz Station GRES-2». 2011. 